\title{
How Developers Explore and Exploit Instant Innovation from Experiment to Implementing New Product Development
}

\author{
Masayoshi Fukushima ${ }^{1}$, Tadashi Takayama ${ }^{2}$, and Makoto Takayama ${ }^{1}$ \\ ${ }^{1}$ Graduate School of Modern Society and Culture, Niigata University, Japan \\ ${ }^{2}$ Graduate School of Business Administration,Kobe University, Japan \\ hnsinteaol.com \\ takayama-tadashi@arion.ocn.ne.jp \\ takayama@mot.niigata-u.ac.jp
}

\begin{abstract}
This paper examines the nascent process of how Dynamic Instant Innovation (DII) is created by ambidexterity which is an individual's capacity to be equally skillful with both hands. The influences of DII on new product development are introduced and analyzed through Holtzman's paradox. This premise states that the greatest paradox that surrounds successful new product development is the need for free, unfettered creativity to complement disciplined, systematic processes [1]. Drawing from this paradox, strategies are proposed for new product development exploration and exploitation. A real case of needle-free injection product developed by the first author is presented using the DII concept.
\end{abstract}

Keywords: Dynamic Instant Innovation, New Product Development, User Specialization. Ambidexterity, Exploration, Exploitation.

\section{$1 \quad$ Introduction}

Under the current hyper competitive environment, Instant Innovation is inevitable in order to be successful and compete. Innovation, according to Schumpeter, is defined by carrying out new combinations [2] which have elements of both continuous innovation and incremental innovation. A disruptive innovation is an innovation that helps create a new market and value network, and eventually disrupts an existing market, displacing an earlier technology. Disruptive innovation is typically simpler, cheaper, and more reliable and convenient than the established technologies that it replaces [3]. DII creates products exponentially faster, cheaper, and can instantaneously disrupt current markets [4]. However, under hypercompetition, the competitive advantage created by DII can often be short lived. This is why successful companies are in constant pursuit of DII.

\section{What is Dynamic Instant Innovation (DII)?}

With the diffusion of more knowledge to more participants in the industry using today's multiplatform communication means, DII can proceed in parallel among 
many open integrated parties and industries. As a result, more parallel experiments are occurring leading to more variety and more choices, which foster more rapid innovation. As such, the concept can be understood as rapid parallel research and development through multi-levels of organizations and individuals across the global spectrum that is loosely integrated by the Internet, thereby leading to Dynamic Instant Innovation. DII differs from user innovation in that user innovation refers to innovation by consumers rather than by suppliers, producers, and/or manufacturers. DII can encompass all of these elements. DII also differs from fusion innovation in that the latter relies on a process by which innovation is fused or comes together over time among the participants in a social system. This concept sometimes comes from happenstance and is not facilitated by formal nor even informal processes. For example, fusion foods have evolved by mixing flavors and recipes from different ethnic foods but not on any wide scale common interest or platform.

Generally speaking, users can experiment, implement and popularize new technology at the same time or instant, which is a form of DII. Its power exceeds that of concurrent engineering and open innovation. DII prevails in the user industries by the following steps:

1. Simultaneous processing of multiple information by reciprocal information exchange,

2. Integration of multiple streams of information into businesses,

3. Specialization of users, and

4. Direct user-created innovation [5]

As von Hippel noted, "Users' abilities to develop high-quality new products and services for themselves are improving radically and rapidly" [6]. The following are examples of DII:

A new scheme of modularization involves adding powerful computations and tabulations for improved efficiency and accuracy to bring about rapid innovation, which is a form of Instant Innovation. Modularization sped up genome sequencing making it possible to sequence 30 billion human genomes in 3 days. Now it is a matter of almost instantaneous sequencing of billions of genomes because of this innovation [4].

This DII is now possible because of exponential convergence of new disruptive innovations. Examples of such converging, disruptive innovations include nanotechnology, wireless sensor, internet, imaging, mobile connectivity, social networking, computing power, data universe, etc., have all contributed to exponential convergence of disruptive innovations.

Another example is DNA arrays that transform genetic sequencing and mapping capabilities. The arrays that are built on the same knowledge domain have limited upside potential whereas those that are built on different complementary knowledge domains could be more valuable as they are not bound by preconceived limitations. This is an indication that DII is also fostering competitive advantages that comes from exploration by ambidextrous employees.

Again, von Hippel noted "Steady improvements in computer software and hardware are making it possible to develop increasingly capable and cheaper tools for innovation that require less and less skill and training to use" [6]. An example of specialization of users by DII is Jack Andraka, a 15-year-old boy who developed a 
new test for pancreatic cancer. After a family friend died from pancreatic cancer, Jack discovered that there was no useful test to detect pancreatic cancer in the early stages when it can be treated. He researched on Google and Wikipedia to learn as much as possible, then put together a proposal to find a way to develop a test for it. He submitted his ideas to 200 doctors and only one gave him some space in his lab. The results are a test that is non-invasive, costs $\$ 0.03$, takes only 5 minutes and is $100 \%$ accurate [7].

Instant Innovation is enhanced by facilitating user specialization through tailored programming, such as downloadable apps, and by co-creating the development with customers. This power shift is enforced by an open-integrated system instead of open innovation. An example of co-creation is FedEx, a company that lets users further into the shipping process of their packages. The online tracking system is a valuable innovation for FedEx customers [8]. This system empowers users to take more control of the process to enabling the monitoring of the status of shipment. This will lead to customer satisfaction, cheaper, faster, better, easier, smarter, informative, participatory, and predictive Instant Innovation.

Holtzman's research illustrates how to utilize innovation to catalyze efficient and effective new product development (NPD). He emphasizes that a strategic innovation approach is indispensable for organization to be successful. Examples cited include (1) industry knowledge and foresight, (2) seeking to understand its customer, provide insight, pinpoint unarticulated customer needs and delight, and deliver on these unmet needs, and (3) strategic alignment internally and externally, with customers and suppliers, exploring long term possibilities and practical implementation activities[1].

It is also illustrated how product and service development is viewed (Fig. 1) as increasingly important as product and service life cycles have become shorter. Introducing new product and services in an efficient manner gives companies a

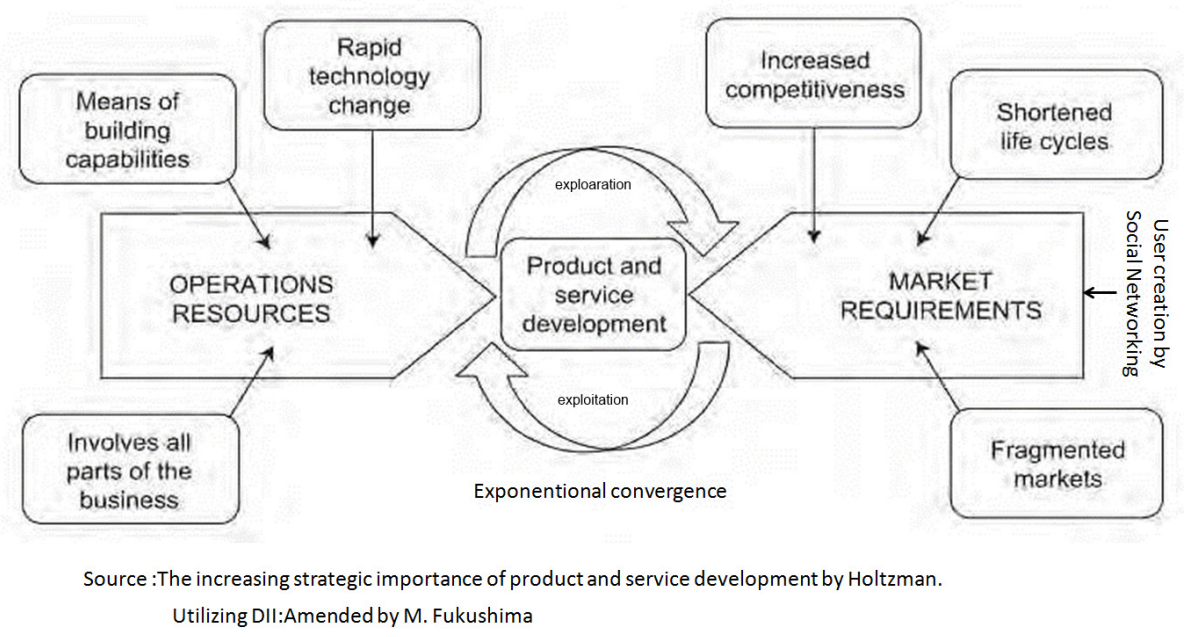

Fig. 1. The increasing strategic importance of product and service development by Holtzman 
competitive edge over competition. The general framework advanced here sees dynamic capabilities (DC) and Dynamic Instant Innovation (DII) as the foundation of enterpriselevel competitive advantage in regimes of rapid (technological) change. The framework indicates that the extent to which an enterprise develops and employs superior (nonimitable) dynamic capabilities will determine the nature and amount of intangible assets it will create and/or assemble and the level of economic profits it can earn [9].

\section{How Dynamic Instant Innovation is Created by Ambidexterity}

In the USA, only about $0.10 \%$ of firms ever achieve revenues of more than $\$ 250$ million in sales and only $0.036 \%$ of those are successful in attaining over $\$ 1$ billion in sales. Most of the new startups failed or stayed small [10] [4]. Hannah's study showed many large firms failed and only 20 firms remained between 1912 and 1995. Other research estimated that even large, well-established, companies can only expect to survive between 6 to 15 years [11] [12] [13]. March emphasizes that the ability of a firm to survive is its employees or users' capacity to be equally skillful with both hands, i.e., be ambidextrous by showing its ability to exploit existing assets and positions in a profit-producing way and simultaneously explore new technologies and market to configure and reconfigure organizational resources to capture existing as well as new opportunities [14]. Therefore, DII is created by exploration and exploitation and becomes the heart of successful people and organization.

Why do startups of needle-free injection systems fail? Initial products may not be user friendly and the designs have many flaws. They are more expensive than needle syringes, hard to load, to read, potentially less accurate, requiring an "air shot", and can be potentially misused. Not surprisingly, the initial products needed to be revised or modified until customers are satisfied, which will be very costly for startups if they conduct such implementation without ambidextrous alliances [10]. O'Reilly argues the ability of a firm to be ambidextrous is at the core of dynamic capabilities and further shows that senior management's ability to sense changes in their competitive environment, including potential shifts in technology [15].Therefore the authors argue that senior management's ability to sense changes in their competitive environment, including potential shifts in technology is enhanced by DII. While the authors have not shown any concrete statistics, methodologies, or hypothesis derived from the theoretical analysis of the ambidextrous theory, whether it generally applies to many companies of the world, the authors emphasize its application to one specific company, "INJEX". Gibson and Birkinshaw (2004) conducted 4,195 interviews from 41 companies from all over the world and verified that ambidextrous employees supported their hypothesis. [16] In the past 20 years, during Japan's economic stagnation, Japanese electronics makers were defeated by Samsung. Kawai illustrated the causes of failure of top management of the Japanese makers in fulfilling responsibilities. The causes of failure include (1) failure to sense, (2) satisfaction with status quo, (3) failure to strategize, less resources, and inability to overcome sectionalism and rigidity, (4) lack of flexibility, and (5) lack of concept of "dynamic 
strategy". Inability to quickly react and forecast are also factors. In contrast, Samsung's top management fulfilled its responsibility and has made Samsung a household name by incorporating factors ignored or not possessed by its Japanese counterparts. Japanese companies were insufficient in fulfilling responsibility concerning both DSC and DRC [17].

Startups need to collaborate with alliances, CVC, and JV, which have specific mechanisms that enable firms to be successful in managing separate "explore-andexploit" subunits and leveraging common assets in ways that permit the firm to adapt to new opportunities and threats. It is the presence of these characteristics that help startups to be successful. The ability to adapt to change like a chameleon by collaborators may need the ability of the senior leadership to manage the conflicts and trade-offs required by ambidexterity [18].

\section{A Real Case of Needle-Free Injection Product Developed by One of the Authors}

Medical devices need to be innovated through "Patient Experience Design" and drug or molecular-driven design perspective, which can be thought of as a system or service design perspective. Adapting to unforeseen circumstances require the ability to act decisively, to be both open-minded and confident, and to have a talent for reading messy or hidden data [19]. INJEX has been successful in collaboration with universities and research organizations in Germany, Singapore, Malaysia, Japan and the USA for many years by not focusing on the deal itself but with value-creating relationships. Intel's success was the company's managed relationships with companies that complement their core business, according to Cusmano [20]. Similarly, INJEX uses direct sales via its own exclusive distributors worldwide as well as beauty clinics and anti-aging clinics directly. Direct sales to market via its own distribution make it competitive and self-reliant, which allows Injex to create strong customer relationships. Injex has successfully entered into niche markets with huge profits such as the beauty market where regulatory and government restrictions are milder than those in the medical field. These fields are neglected by the major needle syringe companies such as Becton Dickinson and Terumo [4]. INJEX created the "Shireen" brand for the niche beauty market. Lead users or early adapters of a product or process may become general in the market place in five to ten years. New niche market has been created in collaboration with Injex and beauty practitioners since they are familiar with conditions which lie in the future for most others, they can serve as a need for casting team for INJEX marketing research. Injex has not competed against major syringe companies directly for the reasons outlined in table 1 . This is followed by a business case of an innovation developed by the author showing how new product development efficiencies are enhanced through the digitalization of merchandise-flow. 
Table 1. Position of existing major to first-generation bio-pharmaceutical and new born biopharmaceutical companies

\begin{tabular}{|c|c|c|}
\hline & $\begin{array}{c}\text { First-generation bio- } \\
\text { pharmaceuticals }\end{array}$ & New born bio-pharmaceuticals \\
\hline Business result & Win & Loss \\
\hline Competition & Direct & Indirect/neutral \\
\hline New products & Replace existing products & Create new markets \\
\hline New product development & Promoted & Neglected \\
\hline
\end{tabular}

\section{$5 \quad$ A Business Case of the Author's Needle-Free Injection Product}

Developing new products is time consuming because of the necessity for improving product design to be user friendly and also for the betterment of product quality. Clearly it is preferable to shorten lead-time for developing new products. It follows such cycle as shown in Fig. 2 below when a new product is developed - from trial production stage to finished mass-production stage.

To shorten the total lead-time for new development, it is required to shorten each cycle. While working on an improved trial product, next stage workers have to battle idle time without productive work. So, it is preferable to produce such trial products when normal production is completed, such as at night or during the holidays. But to change work hours, such as labor-shifts, would be a burden to workers. To solve such issues, the idea of using a 3D Printer is a good solution. 3D Printers allow for the creation of 3D products using a material stratified method. By using a 3D Printer, the process can be set up and allowed to run at the end of normal labor hours without idle time. Then in the morning, the process could be finished and it would be possible to start experimenting immediately. So by utilizing 3D printing, it is possible to eliminate or reduce waiting time during work hours and work can proceed effectively with little waste. Furthermore, workers can produce new products easily without any special training for their work. A planner working as an operator by himself can perform as if he himself was a manufacturer and the use of 3D printing will work effectively to reduce the number of personnel necessary for production. In addition to this $3 \mathrm{D}$ innovation, instantaneous virtual prototyping is possible under DII. Building Information Modeling (BIM) can impact architecture/engineering/construction (AEC). This can provide a virtually simulated and large integrated database. Another concept similar to BIM is a Digital Mock-up (DMU). This will potentially eliminate the inefficient process of transferring large amount of paper based documents. 

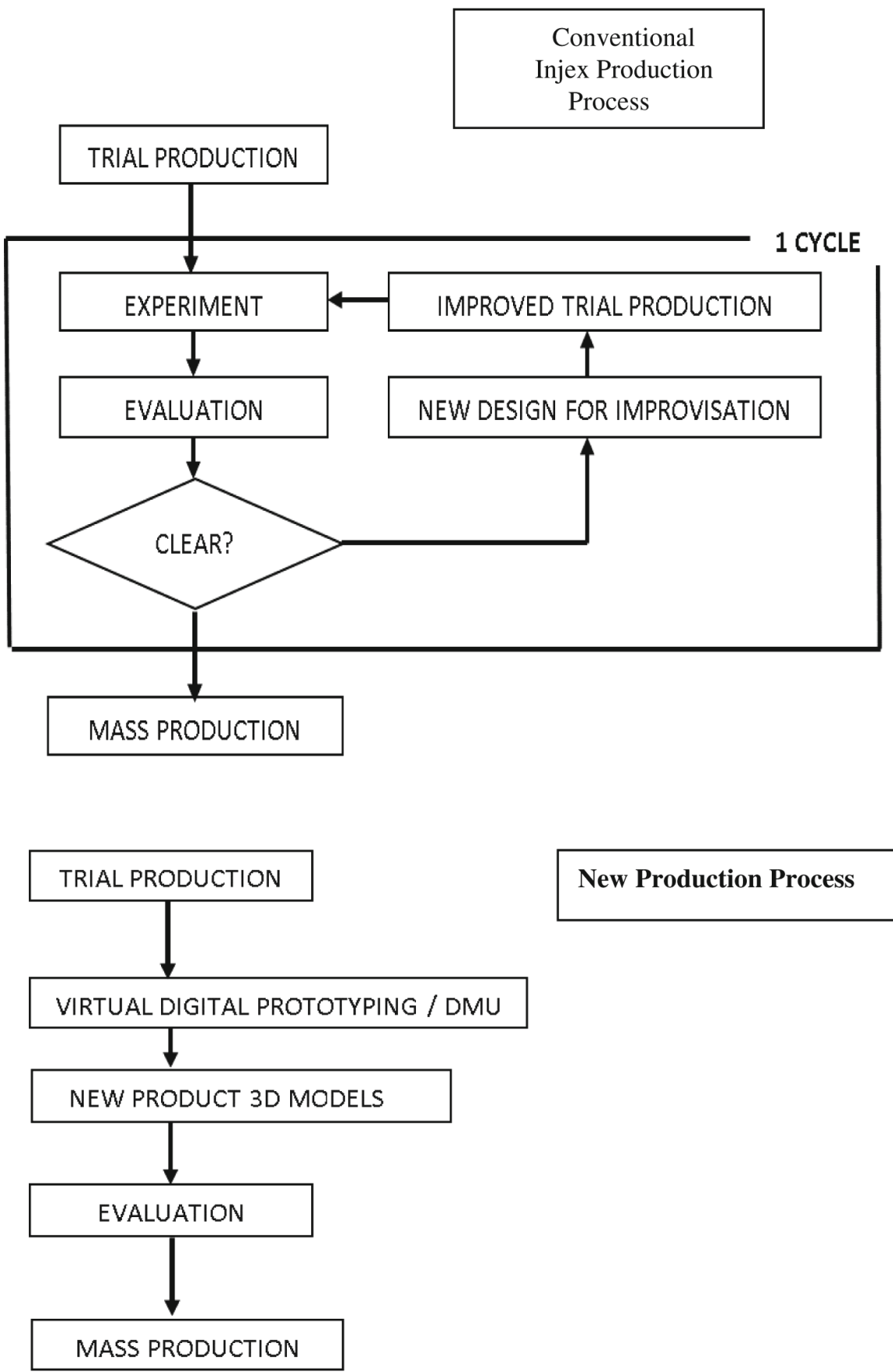

New Production Process

Fig. 2. Flow Chart of New Product Development under DII 


\section{Digitalization of Merchandise-Flow on Needle-Free Injector in the Future by DII}

It is possible to predict different skin hardness for different people, which can cause different volume of drug to dispense under the skin differently even if the same pressure pump is applied to each case (sensing the patient need). That means it is important to individualize each injecting pressure to fulfill proper depth to be achieved (seizing). But it is hard to accommodate such a dynamic requirement with the current fixed mass production system. Therefore, in the near future, if a 3D bioprinter and human genome sequencer could be purchased by each home for general home use, it will be possible to configure or customize an injector for each individual (transforming). For example, a user can scale his own skin-tightness level using a measuring tool to be developed and send data to a manufacturer of needle-free injector (an exogenous technological change that opens up the possibility of new opportunity) [6]. Then the manufacturer produces 3D data for the injector which makes proper depth injection possible. By using such data from the manufacturer, each user can create his or her own injector at home. If this process is established, it would no longer be necessary to manufacture and deliver injectors. Then perhaps only "drug and data" will be necessary in the future. With the present day scientific tools available for genome sequencing, you can know your own genetic makeup. In the future, 3D bio printers assisted by genome analysis, may allow patients to create their own organs and drugs through DII, allowing the patient to make the cure that best fits his or her needs.

\section{The Core Mechanism that Discriminates Between "Winner" and "Loser"}

\section{Strategy:}

Managers should carefully devise a plan of action to efficiently achieve a corporate goal while considering that efficiency as the attainment of maximum value with limited means [21] [22]. INJEX`s strategy is to develop its core competence "needlefree" with patients, medical professionals and distributors. According to von Hippel, innovation is being democratized. A reactive strategy exploits existing knowledge, towards creating stability, consistency and minimizing variation. An innovative strategy uses an explorative approach in order to compete in production innovation [23], yielding disruptive innovation such as NEEDLE-FREE LANCET. Thus, the diffusion process consists of a few individuals who first adopt an innovation then spreads the word among their circles of acquaintances. Such a diffusion process of innovation typically takes a very long time. Since the early Internet era in the 1990s, the use of new technology has spread beyond any imaginable ideas to now allow for experiments and implementations by just about anyone in just about any corner of the world [5]. By reframing the value of a new market such as that of the needle-free injector, the strategy for NPD in the differentiated market is flexible and can be changed due to weak ties. Because of worldwide distributions created in each country, 
INJEX's employees run their own contests and invite everyone into INJEX's innovation process, exploring and exploiting to get the best ideas and technologies from others for INJEX business model, and let others use INJEX innovations in each distributor business model. These innovations are based on tacit knowledge which is very difficult to copy and imitate. Since knowledge is the product of an extended learning process and is an intangible asset that is difficult to acquire and copy, it has been considered a strong source of potential competitive advantage [24]. These distributors and cosmetics professionals spend many years and resources to become an exclusive distributor, by getting approval from the Ministry of Health, and by investing their own time and self-generated content. Hence they are less likely to abandon INJEX. The winners in this new economic environment will be those firms that develop strong internal capabilities in a few areas and leverage those capacities by enlisting the efforts of many others in support of their business [8].

Kawai analyzed the failure of Japanese companies, such as Panasonic, Sharp, and Sony, caused by the new DC (dynamic capability) framework. Strategy-changing capability and dynamic resource-reconfiguring capabilities are discussed. Samsung's success is in changing not only corporate and competitive strategies over time in response to environmental changes (i.e. mobilization of DSC), but also resource configurations in response to shifts in strategies (DRC). Japanese electronics makers failed because of their head-strong decision to sticking to the failed strategy of vertical integration and their failure to restructure their business model (DSC, DRC) [17]. The author posits that catalyzing strategy making for growth or survival by Instant Innovation is the single most important task of top management teams (TMT). The main reason is the lack of DII (failure to create new radical innovations) and the "decision speed" of TMT.

How INJEX crossed the bridge (chasm) over the troubled water:

Linking different types of effective alliances to each distinct stage in the new product development process from discovery to commercialization is one of many key success factors. Understanding more fully the role of firms allying along the entire new product development process seems particularly salient [25]. Two key factors managed within the organization that have enabled INJEX to sustain its competitive advantage are as follow.

1) Vision/Design: The product must be needle-free, less painful, no bruising, easy to use, no stigma, disposable, no needle disposal issues, prefilled drug, fewer mistakes of drug injection, no risk of needle sticks, and convenient in emergency room/trauma center especially with elderly patients.

2) Accurate budgeting: Having a good product to sell is absolutely necessary for cash flow and "on target" budgeting. The first thing to consider in product development is defining MVP (the minimum viable product) and most importantly "will it sell?" What kind of product is the easiest to demonstrate to customers and interested investors? Those two objectives are usually obtainable for most startup companies. The most common problem with startups is keeping costs low and having adequate profit to keep producing the MVP on a regular basis. It is important to have a product to sell to generate cash flow. So, the first objective on the product roadmap should be to define the minimum viable product (the MVP). 


\section{Conclusion}

This paper shows that DII can lead to many breakthroughs, foster innovation, and allow us to live healthier and longer. DII, however, can also shorten the product life cycle placing more stress on management to keep pace. Today's firms face enormous challenges with disruptive innovations such as needle-free injection products. This phenomenon illustrates "agnostic marketing", as described by Christensen, in which it is not known "how", or "how much" new innovations are being used. Facing such uncertainty, managers should get out of their laboratories and directly create knowledge for new customers and new applications through discovery-driven research into the marketplace [3]. Therefore, in challenging the "market change type" innovation, an important point is how to reframe the value of the product. Strong products in the market can limit the capability of NPD. Reframing the value of the new products can unleash the capabilities of NPD. The reframing of the product position is made by flexible weak ties through the alliance that rescues the strategy. By reframing the value of a newly created market, such as that developed by the needle-free injector, the strategy for NPD in the differentiated market is flexible due to weak ties. As a result, reframing the product positioning rescues the strategy from fatal loss in life cycle management and helps the organization maintain competitive advantage.

\section{References}

1. Holtzman, Y.: Utilizing Innovation and Strategic Research and Development to Catalyze Efficient and Effective New Product Development (2012), http: / / www. intechopen. com/download/pdf/31668

2. Schumpeter, J.A.: The theory of Economics Development: An Inquiry into Profits, Capital Credit, Interest and the Business Cycle. Transaction Publishers (1934)

3. Christensen, C.M.: The Innovator's Dilemma: When New Technologies Cause Great Firms to Fail. Harvard Business School Press, Boston (1997)

4. Fukushima, M.: Enabling Instant Access to Medical Care by Disruptive Innovation Without Patient Barriers: Genome Sequencing Using Tablet PCs disrupt the Medical Industry Symposium (Mobile 2013) (2013)

5. Takayama, M., Fukushima, J.M.: Instant Innovation, From Experiment to Implementing New Technology Through The Tablet PC. In: Asia Pacific Conference on Information Management, (APCIM 2012) (2012)

6. von Hippel, E.: Democratizing Innovation. The MIT Press, Cambridge (2006)

7. Jack Andraka: Promising Test for Pancreatic Cancer from a Teenager, TED 2013, Filmed (February 2013), http : / /www. ted. com/ (accessed March 15, 2014)

8. Chesbrough, H.: The Case for Open Services Innovation: The Commodity Trap. California Management Review Spring 53(3) (2011)

9. Teece, D.J.: Dynamic Capabilities \& Strategic Management, p. 48 (2009)

10. McFarland, K.: The Breakthrough Company: How Everyday Companies Become Extraordinary Performer. Crown Business, New York (2008)

11. Awarwal, R., Gort, M.: Evolution of Markets and Entry, Exit, and Survival of Firms. Review of Economics and Statics 78(3) (August 1996)

12. Ormerod, P.: Why Most Things Fail. Pantheon Books, New York (2005) 
13. Charles, I., Knight, M.: The Case of Disappearing Firms. Journal of Organizational Behavior 27(1) (Feburary (2006)

14. March, J.G.: Exploration and Exploitation in Organizational Learning. Organization Science 2(1) (1991)

15. O'Reilly, C.A., Tushman, M.: Organizational Ambidexterity in Action: How Managers Explore and Exploit. California Management Review Summer 2011 53(4) (2011)

16. Gibson, C., Birkinshaw, J.: The Antecedents, Consequences, And Mediating Role of Organizational Ambidexterity. Academy of Management Journal 47(2), 209-226 (2004)

17. Kawai, T.: Responsibilities of Top Management in the flat-Panel TV Wars: An analysis based on the new DC framework. The International Academy of Strategic Management (September 21, 2013)

18. Gilbert, C.: Unbundling the Structure of Inertia. The Ambidextrous Organization. Harvard Business Review 82(4) (April 2004)

19. Pisano, G.: Can Science Be a Business: Lesson from Biotech. Harvard Business School Press (October 2006)

20. Cusumano, M., Gawer, A.: Platform Leadership: How Intel, Microsoft, and Cisco Drive Industry Innovation (2010)

21. Mintzberg, H.: The Rise and Fall of Strategic Planning. The Free Press, New York (1994)

22. Steiner, C., Perry, P.: Achieving Emotional Literacy. London Bloomsbury Publishing (1997)

23. Benner, M.J., Tushman, M.L.: Exploitation, Exploration, And Process Management: The Productivity Dilemma Revisited. Academy of Management Review 28(2), 238-256 (2003)

24. Teece, D.: Economic Performance and the Theory of the Firm (1998)

25. Griffin: Design of Landfills and Integrated Solid Waste Management (1977) 